\title{
Determinants of use of insecticide-treated nets among pregnant women in Nigeria
}

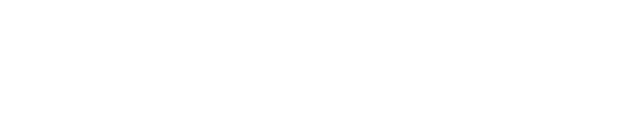

\section{Onoriode Ezire \\ Samson B Adebayo² \\ Omokhudu Idogho 3 \\ Elijah A Bamgboye 4 \\ Ernest Nwokolo ${ }^{5}$}

'Research and Evaluation Division, Society for Family Health, Abuja,

${ }^{2}$ National Agency for Food and Drug Administration and Control, Abuja,

${ }^{3}$ Enhancing Nigeria's Response to HIV \& AIDS, Abuja, ${ }^{4}$ Medical Statistics, University of Ibadan, Ibadan, ${ }^{5}$ Society for Family Health, Abuja, Nigeria
Correspondence: Onoriode Ezire Research and Evaluation Division, Society for Family Health, No 8, Port Harcourt Crescent, Off Gimbiya Street, Area II, Garki, Federal Capital Territory, Abuja, Nigeria

Mobile +234806008 7524

Email oeziree@yahoo.com
Background: Malaria in pregnancy is still a major health issue in Nigeria, accounting for about $33 \%$ of cause of maternal death. Despite massive efforts to make insecticide-treated net (ITN) available to pregnant women in Nigeria, the use is still low. This study was conducted to identify facilitators and inhibitors for the use of ITN/long-lasting insecticidal net (LLIN) among pregnant women in Nigeria.

Methods: Data were obtained from the 2011 State-Specific HIV \& AIDS, Reproductive and Child Health Survey conducted in 18 states of Nigeria. The survey was a population-based study among men and women of reproductive age living in households in rural and urban areas of Nigeria. Multistage cluster sampling technique was used to select eligible respondents. The sample size per state was 960 respondents. Data were collected between October and November 2011. The analysis was done using Statistical Package for Social Sciences (SPSS) version 20. Results: A total of $11.5 \%$ of the respondents were pregnant at the time of the survey of which $73.2 \%$ lived in rural location and approximately $70 \%$ were either not educated or attained at most a primary school education. A total of $93.2 \%$ of respondents have heard of net, $82.6 \%$ were confident that they can hang or use a net, and $64.6 \%$ owned an ITN/LLIN in their household while the actual use was just 19.2\%. We found education, location (urban-rural), confidence to use a net, and knowledge that the use of a net can protect a pregnant woman from malaria to be significant at $5 \%$ level. The number of nets owned per household, the length of time the net is owned, age, and marital status were not significant. Multiple logistics regression shows that pregnant women who are confident to hang or use a net were almost ten times more likely to use a net than those who do not know, while those who know that the use of an ITN/LLIN can protect a pregnant woman from malaria were almost two times more likely to use a net than those who do not know.

Conclusion: In general, while owning a net facilitates its use, ownership does not necessarily translate to usage. Owning more than one ITN/LLIN per household was not significant in the use of an ITN/LLIN by pregnant women in this study, neither was the length of time the net was owned. This study shows that increasing the number of nets owned per household might not be a critical decider on whether the net will be used or not. We recommend massive education on the use of ITN. Skill building on use and increasing knowledge on the benefits of using nets may contribute to improving ITN use among pregnant women in Nigeria.

Keywords: net use in pregnancy, long-lasting insecticidal nets, education, skill building, massive distribution of nets

\section{Introduction}

Malaria still remains one of the main causes of mortality and morbidity in Nigeria and in most Sub-Saharan African countries. ${ }^{1}$ Malaria is endemic in Nigeria, with yearround transmission. In Nigeria, $98 \%$ of all cases of malaria are due to Plasmodium falciparum. This is the species that is responsible for the severe form of the disease that leads to death. It is transmitted from bites of an infected female Anopheles mosquito to 
man. ${ }^{2}$ Prior to 2010, available data were insufficient to clearly microstratify epidemiological profile of Nigeria's malaria. However, the 2010 Nigeria Malaria Indicator Survey revealed that malaria parasite prevalence is still high, with an average prevalence of $42 \%$ among children under the age of 5 years and zonal variations ranging from $28 \%$ in the South East to $50 \%$ in the South West. ${ }^{3}$ Malaria is responsible for mortality in almost one-third of children under 5 years and is associated with one-tenth of maternal deaths in Nigeria. ${ }^{4}$ About $63 \%$ of hospital attendance in Nigeria health care facilities is caused by malaria. ${ }^{4}$ Out of ten childhood deaths, malaria causes three. It is estimated that in every 30 seconds, a child dies of malaria. ${ }^{4}$ The burden is so much that approximately 300,000 children die of malaria annually and over $70 \%$ of illness in children under 5 years is due to malaria; this leads to school absenteeism. Malaria causes abortion and low birth weight in pregnancy. ${ }^{4}$

It has been reported that each year, an estimated 25 million pregnancies are at risk of malaria in Sub-Saharan Africa, the consequences of which can be serious for both mother and fetus in terms of morbidity and mortality. ${ }^{5}$ Malaria in pregnancy is still a major health issue in Nigeria. It accounts for approximately $33 \%$ of cause of maternal death. ${ }^{6}$ Despite massive efforts to make insecticide-treated net (ITN) available to pregnant women in Nigeria, the use is still low. ${ }^{3}$

The National Malaria Control Strategic Plan (NMCSP) addresses national health and development priorities, including the Roll Back Malaria goals and the Millennium Development Goals. The NMCSP priority is increasing possession and use of ITNs and long-lasting insecticidal nets (LLINs), especially among children under 5 years and pregnant women. ${ }^{7}$ Prevention and treatment of malaria in pregnancy is one of the three core interventions of the 2009-2013 NMCSP. ${ }^{7}$ The updated NMSP focuses on household ownership of at least two LLINs with the objective of increasing LLIN use to $80 \%{ }^{7}$

The evidence for the efficacy of ITNs in preventing malaria infection ${ }^{8}$ and its consequences in pregnancy is strong, as reported in a Cochrane review in $2009^{9}$ and in a more recent meta-analysis, ${ }^{10}$ which examined malaria prevention in pregnancy datasets from different African nations. The evidence showed a strong correlation between the use of ITNs and reduction in stillbirths, improvements in birth weights of babies, and a reduction in the prevalence of parasitemia and anemia in pregnant women. A communal protective effect of ITNs and reduction in the overall vector density have also been observed in some settings. ${ }^{11}$

Despite the known health benefits of using ITN in pregnancy, the use is still very low $(16.4 \%$ and $16.0 \%$ for ITN and LLIN, respectively) ${ }^{12}$ with wide variation across geopolitical zones. Understanding the profile of users can provide very useful information in understanding the facilitators and/ or inhibitors for the use of ITN among pregnant women. In this study, we attempt to answer the question: What are the facilitators for net use among pregnant women? We also sought to answer the questions: Which population subgroups of pregnant women should be targeted to scale-up ITN use? What messages should be reinforced and what skills should be built to promote the use of an ITN/LLIN?

\section{Materials and methods}

Data for the study were sourced from the 2011 State-Specific HIV \& AIDS, Reproductive and Child Health Survey (SARHS). This was a population-based study aimed at assessing and monitoring levels of, and trends in, various indicators of maternal, sexual, and reproductive health issues in 18 Nigerian states (Akwa Ibom, Bauchi State, Benué, Cross River State, Delta State, Edo State, Jigawa State, Kaduna State, Kano State, Katsina State, Kebbi State, Lagos State, Nasarawa State, Ogun State, Oyo State, Rivers State, Sokoto State, and Zamfara State). It had a sample size of 17,280 (ie, 960 per state). Data were weighted to accommodate differences in population size. Ethical approvals were sought and obtained from the Nigerian Institute of Medical Research (one of the Institutional Review Board in Nigeria). A consent form was administered to the respondent before each interview was conducted.

Eligible respondents for this survey were women aged 15-49 years and men aged 15-64 years. Selection was through a stratified probability sampling technique based on locality. Individual respondents were selected within households in various enumeration areas (EAs) across the country. EA is a small area in a community composed of one or more neighboring blocks. In Nigeria, EAs were created by the National Population Commission for the 2006 Census. EAs are the basic units for enumeration. Within a state, all eligible persons, irrespective of their place of residence (rural or urban), were given an equal chance of being included in the final sample. Using an appropriate formula that allows for comparison between the baseline and subsequent follow-up studies, sample sizes were calculated based on a $5 \%$ level of significance and $80 \%$ power of the test. Questionnaires were pretested and administered by trained interviewers under the supervision of seasoned researchers.

\section{Data}

The dataset used for this analysis was from the dataset of SARHS 2011. In total, the dataset consists of 16,032 respondents' responses with females accounting for $40.7 \%$ 
of the responses. We limited our analysis to 850 women who reported that they were pregnant at the time of the survey.

\section{Analysis}

Data were entered and cleaned using Census and Survey Processing System software. Analysis was done using Statistical Package for Social Sciences (SPSS) version 20. Chi-square test was used to test the significance of selected demographic variables on the use of net. Multiple logistic regression was used to estimate the strength of the association.

\section{Variables in the analysis Dependent variable}

Pregnant women's use of an ITN/LLIN is the dependent variable in this study. For the purpose of this study, we used the number that reported sleeping under mosquito net the last night before the survey. The variable is coded 1 if the respondents slept under a net and 0 if not.

\section{Independent variables}

Independent variables used in the study include:

1. Place (locality) of residence: Place of residence was measured based on whether the respondent resided in an urban or rural area at the time of the survey. This was coded as 1 if the respondent resided in an urban area and 0 if the respondent resided in a rural area.

2. Age of the respondents: The current age of the respondent was measured in years, and this ranged between 15 years and 49 years. Age was included as a categorical variable in all models and subdivided into 15-19 years, 20-24 years, 25-29 years, 30-34 years, 34-39 years, and 40-49 years.

3. Educational attainment: Educational attainment was categorized into five categories: no education, Quranic only, at most primary, at most secondary, and tertiary. In the multiple regression analysis, two dummy variables were created for educational attainment: attained at least a secondary school education or not. Attained at least a secondary school education is coded 1 and not is coded 0 . The second dummy created is never attended a formal school or have some level of formal education, with some level of formal education coded 1 and never attended formal school coded 0 (reference group).

4. Marital status: Marital status was grouped into three categorical variables: married or cohabiting, formally married (divorced, separated, or widowed), and never married. In the multivariate analysis, married or cohabiting and formally married were grouped and coded 1, while never married was coded 0 (reference group).
5. Ever heard of nets: Ever heard of a mosquito net or ITN was measured as yes or no. Yes was coded 1, while no was coded 0 .

6. Ownership of net: Respondents were asked if they own a mosquito net or ITN. Those who responded affirmative were coded 1 , while no was coded 0 .

7. Average number of nets owned per household: We attempted to tease out the effect of number of nets owned on use. We came up with four categories based on respondents' responses: owns one net, owns two nets, owns three nets, and owns four or more nets.

8. Length of time ITN is owned: We created two variables from this by categorizing length of time: an ITN/ LLIN is owned 0-6 months and more than 6 months (variable 1) and 0-12 months and more than 12 months (variable 2).

9. Confidence can hang and use a net: Information on the ability and confidence to hang and use a net was solicited. Those who reported they can hang and use a net were coded 1, while those who cannot were coded 0 .

10. Knowledge that sleeping under a net protects pregnant women from malaria: Respondents were asked questions on the awareness of benefits of using a net. Those who knew that the use of net (mosquito net or ITN) can protect pregnant women from malaria were coded 1, while those who did not know were coded 0 .

\section{Results}

\section{Characteristics of the study population}

About $12 \%$ of the total respondents reported that they were pregnant at the time of the survey. An analysis of demographic characteristics of those who reported that they were pregnant at the time of survey (Table 1) shows that approximately $56 \%$ were aged $20-34$ years, while over $90 \%$ were either married or cohabiting with a partner. In terms of education, as much as $38 \%$ had no education, while over $70 \%$ resided in rural localities.

\section{Knowledge, ownership, and use of ITN among pregnant women}

Awareness of net is very high among studied pregnant women (92\%). Eight out of every ten pregnant women were confident that they can use or hang a net, while almost four out of ten knew that the use of an ITN/LLIN can protect a pregnant woman from malaria. Ownership of at least one ITN/LLIN in a household was just $67 \%$, while the use was as low as 19\% among all women who are pregnant. Among women who owned at least one net in a household, the use was $29.9 \%$ (Figure 1 ). 
Table I Background characteristics of study population

\begin{tabular}{ll}
\hline Background characteristics $(\mathbf{n}=\mathbf{8 5 0})$ & $\%$ \\
\hline Age category & \\
I5-19 years & 12.2 \\
20-24 years & 22.5 \\
$25-29$ years & 23.2 \\
$30-34$ years & 17.7 \\
35-40 years & 15.7 \\
40-49 years & 8.7 \\
Marital status & \\
Married or cohabiting & 94.2 \\
Never married & 3.2 \\
Formally married & 2.6 \\
Educational attainment & \\
No education & 36.8 \\
Quranic only & 14.1 \\
Primary only & 19.3 \\
Secondary & 25.2 \\
Tertiary & 4.6 \\
Location (urban-rural) & \\
Urban & 26.8 \\
Rural & 73.2 \\
Total & 100.0 \\
\hline
\end{tabular}

\section{Bivariate analysis}

Findings from bivariate analysis are shown in Table 2. The independent variables were tested at 5\% level of significance. The result shows that location $(P=0.020)$, educational attainment $(P=0.001)$, ever heard $(P=0.002)$, ownership $(P<0.0001)$, confidence to hang and use a net $(P<0.0001)$, and knowledge that sleeping under an ITN/ LLIN can protect pregnant women from malaria $(P<0.0001)$ were significant variables. Marital status, age, length of time a woman owns a net, and the average number of nets owned in a household were not significant. The relationship between the use of nets and education is positive, meaning that the higher the level of education, the higher the level of use of an ITN/LLIN.

\section{Multivariate analysis of factors associated with the use of ITN among pregnant women}

Multivariate analysis was conducted using multiple logistic regression in an attempt to establish possible association between the use of ITN by pregnant women and some independent variables. Goodness-of-fit test was based on Hosmer-Lemeshow test ${ }^{13}$ with a $P$-value of 0.750 . Only variables that were significant using chi-square test were included in the logistics regression model, and they include location (with urban location as the reference); educational attainment (with at most primary or Quranic education as the reference), ever heard of nets (never heard as the reference), confidence to hang or use a net, and knowledge that the use of an ITN/LLIN can protect pregnant woman from malaria.

At $5 \%$ level of significance, we found only two of the independent variables to be significant: confidence to hang or use a net $(P=0.002)$, and knowledge that the use of nets can protect a pregnant woman from malaria $(P=0.012)$. At $10 \%$ level of significance, educational attainment was significant $(P=0.099)$. The other variables used in the logistics regression were not significant.

Pregnant women who know how to hang or use a net were found to be almost ten times more likely to use a net compared with pregnant women who do not know how to use or hang a net (odds ratio [OR]: 9.506; 95\% confidence interval [CI]: 2.276 and 39.700). Pregnant women who know that the use of an ITN/LLIN can protect a pregnant woman against malaria were found to be almost two times more likely to use a net compared with those who do not know

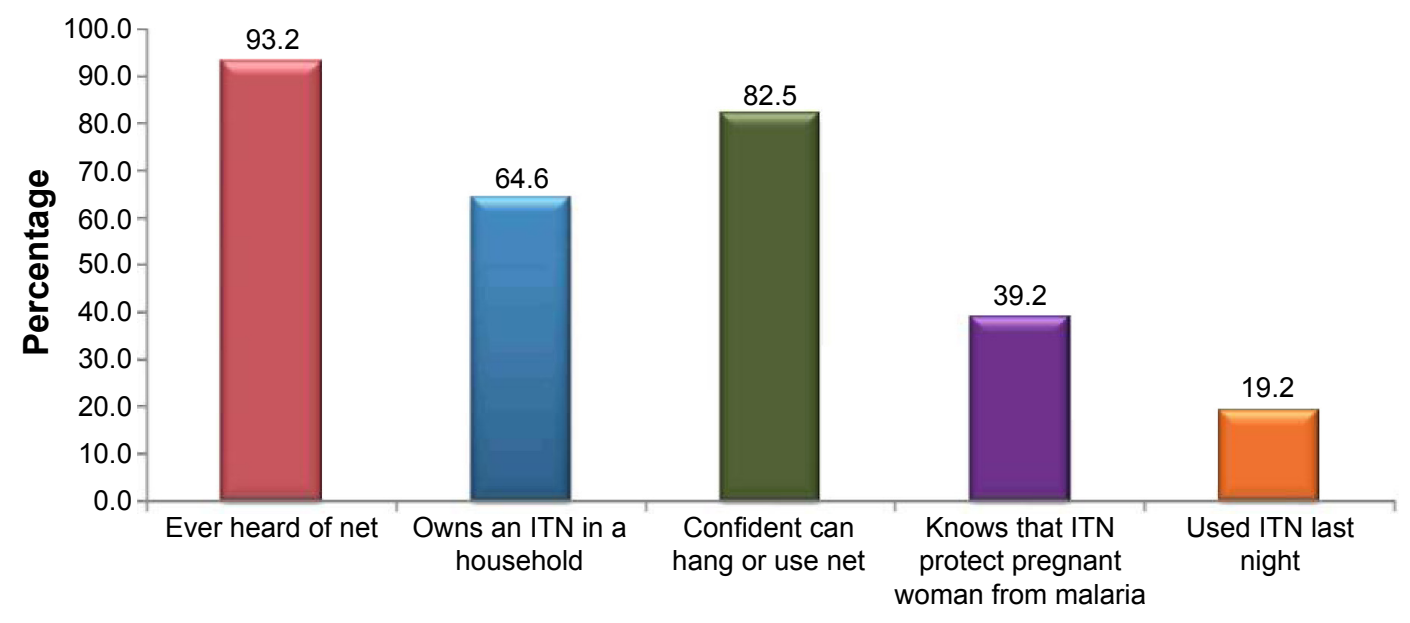

Figure I Proportion of pregnant women who have ever heard of a net, own a net, are confident can hang or use a net, and slept under a net. Abbreviation: ITN, insecticide-treated net. 
Table 2 Percentage of pregnant women who slept under ITN the last night before the survey by selected characteristics

\begin{tabular}{|c|c|c|}
\hline Selected characteristics $(n=850)$ & $\%$ & $P$-value \\
\hline \multicolumn{3}{|l|}{ Age category I } \\
\hline $15-19$ years & 21.2 & 0.129 \\
\hline 20-24 years & 25.1 & \\
\hline $25-29$ years & 18.8 & \\
\hline $30-34$ years & 15.3 & \\
\hline $35-40$ years & 18.0 & \\
\hline $40-49$ years & 12.2 & \\
\hline \multicolumn{3}{|l|}{ Marital category } \\
\hline Married or cohabiting & 19.8 & 0.221 \\
\hline Never married & 7.4 & \\
\hline Formerly married & 13.6 & \\
\hline \multicolumn{3}{|l|}{ Educational attainment } \\
\hline No education & 21.7 & 0.001 \\
\hline Quranic only & 30.8 & \\
\hline Primary only & 14.0 & \\
\hline Secondary & 13.1 & \\
\hline Tertiary & 17.9 & \\
\hline \multicolumn{3}{|l|}{ Location (urban-rural) } \\
\hline Urban & 14.5 & 0.020 \\
\hline Rural & 20.9 & \\
\hline \multicolumn{3}{|c|}{ Level of education (at least primary or Quranic education) } \\
\hline Some education & 17.7 & 0.089 \\
\hline No education & 21.7 & \\
\hline \multicolumn{3}{|c|}{ Level of education (at least a secondary school education) } \\
\hline Secondary or tertiary & 13.8 & 0.018 \\
\hline Primary of Quranic & 21.1 & \\
\hline \multicolumn{3}{|l|}{ Ever heard of nets } \\
\hline No & 5.3 & 0.002 \\
\hline Yes & 20.3 & \\
\hline \multicolumn{3}{|l|}{ Owns a net } \\
\hline No & 0.3 & 0.0001 \\
\hline Yes & 29.7 & \\
\hline \multicolumn{3}{|l|}{ Confident to hang or use a net } \\
\hline No & 3.4 & 0.0001 \\
\hline Yes & 22.7 & \\
\hline \multicolumn{3}{|c|}{ Knows that use of an ITN/LLIN can prevent malaria in pregnancy } \\
\hline No & 14.0 & 0.0001 \\
\hline Yes & 27.5 & \\
\hline \multicolumn{3}{|l|}{ Length of time net is owned } \\
\hline Within last 6 months & 27.8 & 0.322 \\
\hline More than 6 months & 30.5 & \\
\hline \multicolumn{3}{|c|}{ Length of time net is owned (at least 12 months) } \\
\hline Within 12 months & 30.1 & 0.487 \\
\hline More than 12 months & 29.5 & \\
\hline \multicolumn{3}{|c|}{ Number of nets owned by household (one net) } \\
\hline Owns one net & 30.4 & 0.487 \\
\hline More than one net & 29.6 & \\
\hline \multicolumn{3}{|c|}{ Number of nets owned by household (at least two nets) } \\
\hline Owns at most two nets & 28.2 & 0.067 \\
\hline Owns more than two nets & 35.8 & \\
\hline \multicolumn{3}{|c|}{ Number of nets owned by household (at least three nets) } \\
\hline Owns at most three nets & 28.2 & 0.023 \\
\hline Owns more than three nets & 40.4 & \\
\hline \multicolumn{3}{|c|}{ Number of nets owned by household (two nets) } \\
\hline Owns two nets & 26.9 & 0.080 \\
\hline More or less than two nets & 32.7 & \\
\hline
\end{tabular}

Abbreviations: ITN, insecticide-treated net; LLIN, long-lasting insecticidal net. that the use of an ITN/LLIN can protect a pregnant woman from malaria (OR: 1.813; 95\% CI: 1.142 and 2.877). Detailed findings are shown in Table 3.

\section{Discussion}

The use of an ITN/LLIN by pregnant women is a strongly recommended approach to malaria prevention in pregnancy as it ensures not only the mother's health but also that of the fetus. ${ }^{7}$ The result shows that only $19.2 \%$ of pregnant women slept under a net the last night before the survey. In this study, we attempted to find some of the facilitators of ITN/LLIN use among pregnant women. We deduce from the results that confidence to use or hang an ITN/LLIN and knowledge that the use of an ITN/LLIN can protect a pregnant woman from malaria are facilitators to use an ITN/LLIN by pregnant women. We also found some significant differences between rural and urban locations, those with at least secondary education and those without, such that the higher ones level of education, the less likelihood of using an ITN/LLIN. In terms of messages to be reinforced and skills to be built, we found messages on knowledge that the use of an ITN/LLIN can protect a pregnant woman from malaria and skills on how to hang or use a net to be very significant.

With over $90 \%$ of pregnant women being aware of nets, malaria interventions, especially those targeting pregnant women, need to go beyond creating awareness on net use to deepening knowledge and skills on the benefits of using and also building skills on the use of an ITN/LLIN. Interpersonal communications and community engagement has been shown in some other studies as very good options to increase knowledge and build skills. ${ }^{14,15}$ While ownership of a net is very significant, we did not find a significant relationship with the number of nets owned, the length of time the household has owned the net, and the actual use of the net. This seems to suggest that the use of a net is not necessarily a function of the number of nets owned but having the right information and skills to use it.

The findings of this study are close to what were found in some other studies that identified the need to scale-up community awareness and malaria education to promote net use in Nigeria. ${ }^{14,15}$ Marital status and age, like in most other studies, were not significant variables explaining the use of nets among pregnant women. Ankomah et al ${ }^{16}$ found that pregnant women who listened to mass media were more likely to adopt strategies to protect themselves from malaria and recommended that behavior change communication messages that aimed at promoting net use and antenatal attendance are necessary in combating malaria. ${ }^{16}$ Our findings suggest that the messages should be tailored toward 
Table 3 Result of multiple logistics regression

\begin{tabular}{|c|c|c|c|c|}
\hline & \multirow[t]{2}{*}{$P$-value } & \multirow[t]{2}{*}{ OR } & \multicolumn{2}{|l|}{$95 \% \mathrm{Cl}$} \\
\hline & & & Lower & Upper \\
\hline Location (urban-rural) & 0.368 & 1.258 & 0.763 & 2.072 \\
\hline Had at least a secondary education & 0.099 & 1.496 & 0.926 & 2.415 \\
\hline Ever heard of nets & 0.258 & 2.364 & 0.532 & 10.497 \\
\hline $\begin{array}{l}\text { Knows that the use of an ITN/LLIN can } \\
\text { protect pregnant woman from malaria }\end{array}$ & 0.012 & 1.813 & 1.142 & 2.877 \\
\hline Confident can hang or use a net & 0.002 & 9.506 & 2.276 & 39.700 \\
\hline Constant & 0.0001 & 0.006 & & \\
\hline
\end{tabular}

Abbreviations: OR, odds ratio; $\mathrm{Cl}$, confidence interval; ITN, insecticide-treated net; LLIN, long-lasting insecticidal net.

building skills and messages that increase pregnant women's knowledge of the benefit of using an ITN/LLIN.

We found no significant difference between those who own just one net and those who own more than one net in a household, implying that while ownership of net is important, actual number owned by a household does not significantly determine the use. This sounds contrary as there is huge programmatic emphasis on each household owning at least two nets. ${ }^{17}$ It may be useful to own more than one net in a household, but real focus should be on promoting right knowledge and building skills on net use. In a resourceconstrained environment like that of Nigeria and most Sub-Saharan African countries, decisions need to be made on where investment should be directed. This evidence among others can provide some insight in making these decisions. We also found that the length of time pregnant women own a net is not significant in explaining the use. This suggests that interventions targeting net use, including those distributing ITN/LLIN, can commence anytime in the woman's life.

We did not explore other possible options pregnant women are using to protect themselves against malaria. It is possible that those more educated or living in urban location are using other ways to prevent malaria in pregnancy. Our analyses were also limited to 18 Nigerian states where data collection was done. We recommend that other research should explore to know whether educated and/or urban-based pregnant women prefer and/or are using other methods to prevent malaria in pregnancy. The main objective of the State-Specific HIV \& AIDS, Reproductive and Child Health Survey, which produced the dataset used, was not primarily to collect data on net use. Questions on net use were included as part of the broad issues of reproductive health of women. The dataset could thus be subject to multivariate factors influencing answers or outcomes. Differences in development across the states were also not considered in the analysis. It is possible that this could have some effects on the result. Finally, we did not observe respondents actually hanging or using nets, and we depended on their responses of either yes or no to the question "how confident are you to hang or use a net" with yes I am confident and no I am not as possible responses.

\section{Conclusion}

In this study, we found some variables that significantly explain the use of an ITN/LLIN among pregnant women (confidence to hang or use an ITN/LLIN and knowledge that the use of an ITN/LLIN can protect a pregnant woman from malaria). We also found out that just increasing the number of nets per household is not enough to promote the use of an ITN/LLIN among pregnant women. We strongly recommend education of all categories of women on the benefits of using an ITN/LLIN. It is important that skills should be built on the use of a net as these may contribute to improve ITN/LLIN use among pregnant women in Nigeria.

Cost-effectiveness analysis of the current strategy of two nets per household is recommended as future work. Nigeria is a resource-constrained country; investment must be tailored toward those interventions that give higher rate of returns.

\section{Acknowledgments}

We acknowledge the authors of previous work on the issue we studied, especially the Nigeria National Malaria Elimination Programme. We also appreciate and acknowledge the field team that collected the data and those who supervised data collection. We appreciate Society for Family Health, the organization that conducted SARHS.

\section{Author contributions}

OE wrote the concept, methodology, and contributed in the data analysis and discussion; SA contributed in the data analysis and discussion session; OI reviewed related literatures and also contributed in the "Discussion" section and "Conclusion" section; EB contributed in the data analysis, 
discussion, and conclusion sessions; EN contributed in the review of literature, discussion, and conclusion. All authors contributed toward data analysis, drafting and revising the paper and agree to be accountable for all aspects of the work.

\section{Disclosure}

The authors report no conflicts of interest in this work.

\section{References}

1. WHO. World Malaria Report 2013. Geneva: WHO; 2013.

2. Lagos State Government. Lagos State Ministry of Health. [Online]; 2014. Available from: http://www.lagosstateministryofhealth.com/ programme_info.php?programme_id=6. Accessed October 22, 2014.

3. National Population Commission, ICF International. Nigeria National Malaria Indicator Survey. Abuja: ICF Macro; 2012.

4. Federal Ministry of Health. Nigeria National Guidelines for Diagnosis and Treatment of Malaria. Abuja: Federal Ministry of Health; 2011.

5. Desai M, ter Kuile FO, Nosten F, et al. Epidemiology and burden of malaria in pregnancy. Lancet Infect Dis. 2007;7(2):93-104.

6. National Population Commission. Nigeria Demographic Health Survey. Abuja: Macro; 2008.

7. Federal Ministry of Health. Nigeria National Malaria Control Strategic Plan. Abuja: Federal Ministry of Health; 2014.

8. Binka FN, Kubaje A, Adjuik M, et al. Impact of permethrin impregnated bednets on child mortality in Kassena-Nankana district, Ghana: a randomized controlled trial. Trop Med Int Health. 1996;1(2):147-154.
9. Gamble CL, Ekwaru JP, Kuile FO. Insecticide-treated nets for preventing malaria in pregnancy. Cochrane Database Syst Rev. 2009;38(1): 36-37.

10. Pell C, Straus L, Andrew EV, Meñaca A, Pool R. Social and cultural factors affecting uptake of interventions for malaria in pregnancy in Africa: a systematic review of the qualitative research. PLoS One. 2011; 6:1-14.

11. Pulford J, Hetzel MW, Bryant M, Siba PM, Mueller I. Reported reasons for not using a mosquito net when one is available: a review of the published literature. Malar J. 2011;10:83.

12. National Population Commission. Nigeria National Demographic Survey. Abuja: Macro; 2013.

13. Hosmer D, Lemeshow S. Applied Logistic Regression. 3rd ed. New Jersey, NJ, USA: John Wiley and Sons; 2013.

14. Ukibe SN, Mbanugo JI, Ukibe NR, Ikeakor LC. Level of awareness and use of insecticide treated bed nets among pregnant women attending antenatal clinics in Anambra State, South Eastern Nigeria. J Public Health Epdemiol. 2013;5(9):391-396.

15. Ezeama M, Ezeamah F. Geneva Health Forum. [Online]; 2013. Available from: http://ghf.g2hp.net/2013/07/19/the-use-of-insecticidetreated-nets-among-pregnant-women-in-nigeria/\#.VE-j7NhOUlY. Accessed October 28, 2014.

16. Ankomah A, Adebayo SB, Arogundade ED, et al. The effect of mass media campaign on the use of insecticide-treated bed nets among pregnant women in Nigeria. Malar Res Treat. 2014;2014:694863.

17. Federal Ministry of Health. Nigeria National Malaria Control Strategic Plan 2009-2013. Abuja: Nigeria Malaria Control Programme; 2009.
International Journal of Women's Health

\section{Publish your work in this journal}

The International Journal of Women's Health is an international, peerreviewed open-access journal publishing original research, reports, editorials, reviews and commentaries on all aspects of women's healthcare including gynecology, obstetrics, and breast cancer. The manuscript management system is completely online and includes

\section{Dovepress}

a very quick and fair peer-review system, which is all easy to use. Visit http://www.dovepress.com/testimonials.php to read real quotes from published authors.

\footnotetext{
Submit your manuscript here: http://www.dovepress.com/international-journal-of-womens-health-journal
} 